\title{
Cardiovascular and Other Competing Causes of Death in Male Breast Cancer Patients: A Population-Based Epidemiologic Study
}

Hanbin Zhang, (D) 'Wenrui Lin, ${ }^{2}$ Dongting Chen,' Kenie Wang, ${ }^{3}$ Wei Tu, ${ }^{4}$ Huiwen Lin, ${ }^{4}$ Kun Li, ${ }^{4}$ Shangzhu Ye, ${ }^{5}$ Tianwang Guan, (1D) ${ }^{6}$ Yuerong Chen ${ }^{4}$

'Department of Clinical Medicine, The Second Clinical College of Guangzhou Medical University, Guangzhou, People's Republic of China; ${ }^{2}$ Department of Clinical Medicine, The Sixth Clinical College of Guangzhou Medical University, Guangzhou, People's Republic of China;

${ }^{3}$ The First Department of Breast Cancer, Tianjin Medical University Cancer Institute and Hospital, National Clinical Research Center for Cancer, Tianjin, People's Republic of China; ${ }^{4}$ Department of Oncology, Jinshazhou Hospital of Guangzhou University of Chinese Medicine, Guangzhou, People's Republic of China; ${ }^{5}$ Department of Ophthalmology and Otorhinolaryngology, Yangjiang Hospital of Traditional Chinese Medicine, Yangjiang, People's Republic of China; ${ }^{6}$ Department of Cardiology, Laboratory of Heart Center, Zhujiang Hospital, Southern Medical University, Guangzhou, People's Republic of China

Correspondence: Tianwang Guan Department of Cardiology, Laboratory of Heart Center, Zhujiang Hospital,

Southern Medical University, Guangzhou, People's Republic of China

Tel +8620-6I643888

Email guantianwang@।63.com

Yuerong Chen

Department of Oncology, Jinshazhou Hospital of Guangzhou University of Chinese Medicine, Guangzhou, People's

Republic of China

Tel +8620-8I I I666I

Email604910344@qq.com
Purpose: Male breast cancer (MBC) is a rare disease that tends to occur in elderly men. Little is known about the causes of death in MBC because of the small sample size of most studies. This study aimed to investigate the causes of death in MBC patients.

Patients and Methods: MBC patient data were obtained from the Surveillance, Epidemiology, and End Results database (1975-2016). Time trends of MBC mortality in the US population were analyzed using Joinpoint software. We calculated the proportion of each cause of death in the overall cohort and in different patient subgroups. Competing risk models were used to calculate cumulative mortality at different follow-up times. The risk of cardiovascular death (CVD) in MBC patients was compared to that of the age-matched general population by calculating standardized mortality ratio (SMR).

Results: In total, 6426 patients were included in the analysis. MBC mortality rate increased between 2004 and 2019 (annual percentage change=1.16, 95\% confidence interval [CI]: $0.50,1.80)$. There were 1757 patients $(27.3 \%)$ who died of non-breast cancer causes. CVD was the leading cause of death in patients who were elderly or had localized disease. MBC patients had a 6.58-fold higher risk of CVD than the general population (SMR=6.58, 95\% CI: 6.14, 7.05).

Conclusion: Non-breast cancer death accounts for the majority of deaths in MBC patients who are elderly or have localized cancer. Compared to the general population, MBC patients have an increased risk of CVD. These results highlight the importance of monitoring cardiovascular comorbidities in MBC patients.

Keywords: male breast cancer, cardio-oncology, elderly patients, cause of death, non cancer death, cardiovascular death

\section{Introduction}

Male breast cancer (MBC) is rare, accounting for approximately $1 \%$ of breast cancer cases and $<1 \%$ of malignancies in men. ${ }^{1,2}$ It is estimated that 2650 new MBC cases will be diagnosed and 530 men will die of this disease in the US in $2021{ }^{3}$ The incidence of $\mathrm{MBC}$ is increasing. ${ }^{4-6}$ Owing to its rarity, not many clinical studies have been carried out in $\mathrm{MBC}$ patients ${ }^{1}$ and treatment strategies have mostly been extrapolated from research on female breast cancer (FBC). ${ }^{7}$ However, $\mathrm{MBC}$ is distinct from $\mathrm{FBC}$ in both biological and clinical features; ${ }^{8,9}$ therefore, optimal management strategies also differ. $^{10,11}$ Most previous researches on MBC were small single-center case series that did not yield clear evidence, ${ }^{7}$ which has limited progress in the improvement of MBC prognosis. Large-scale studies of MBC are needed to fill the gap in knowledge. 
Non cancer death accounts for a large proportion of deaths in breast cancer survivors; thus, identifying and controlling risk factors for mortality can improve patients' overall survival. ${ }^{12}$ Previous studies have shown that non cancer death - especially from cardiovascular causesaccounts for the largest proportion of deaths in FBC patients. $^{13,14}$ Evidence-based clinical guidelines of the American Society of Clinical Oncology (ASCO) $)^{15}$ and statements from the American Heart Association ${ }^{16}$ have highlighted non cancer diseases associated with FBC and provide recommendations for their monitoring and management. However, the causes of death in MBC patients have rarely been reported; a few studies that examined different causes of death reported a high rate of noncancer death, ${ }^{17,18}$ although these studies had small sample sizes and may not reflect the actual epidemiology of MBC. $\mathrm{MBC}$ tends to occur at an older age than $\mathrm{FBC}^{7,19}$ and therefore, patients have a higher risk of cardiovascular disease and other comorbidities.

The first as well as the latest ASCO guidelines on MBC propose additional studies to provide evidence for post-treatment surveillance and management. ${ }^{7}$ To identify high risk diseases in certain groups of MBC survivors is the basic of precise surveillance and management. To this end, we conducted a population-based analysis of data from the Surveillance, Epidemiology, and End Results (SEER) database in order to identify high-risk diseases causing mortality in MBC patients, including in different patient subgroups. We mainly focused on the risk of cardiovascular and other causes of death in MBC patients and their cardiovascular death (CVD) risk was compared to the general population. Our findings can help clinicians monitor and manage high-risk conditions as well as balance cancer treatment side effects and benefits in MBC patients in order to maximize their overall survival.

\section{Materials and Methods}

\section{Data Source}

Data for this population-based analysis were downloaded using SEER*Stat v8.3.7 software (National Cancer Institute, Bethesda, MD, USA) from the SEER-18 database, which contains data from 18 cancer registries in the US covering approximately $34.6 \%$ of the US population. ${ }^{20}$ We obtained permission to retrieve and use the data after signing the data use agreement. Data on men in the general population who died from breast cancer between 1999 and 2019 were downloaded from the Centers for Disease
Control and Prevention Wide-ranging Online Data for Epidemiologic Research (CDC WONDER) ${ }^{21}$ for time trend analysis. Data for a standardized cohort reflecting the US general population were also obtained from CDC WONDER. ${ }^{21}$ Ethics approval and informed consent were not required as the data were publicly available.

\section{Study Population and Variables}

This was a population-based epidemiologic study spanning a long period (42 years). The inclusion criteria were as follows: (1) diagnosed with $\mathrm{MBC}$ as the primary tumor; (2) diagnosed between 1975 and 2016; and (3) active follow-up and clear cause of death. The exclusion criteria were as follows: (1) death certification or autopsy only; and (2) multiple primary cancers. Patients aged 0-34 years were excluded from the competing risk analysis and standardized mortality ratio (SMR) calculation due to their small number. Patient data that were extracted from the database included age at diagnosis, marital status, race, year of diagnosis, grade, laterality, stage, surgery, radiation, and chemotherapy.

\section{Study Design and Outcomes}

We first analyzed time trends of breast cancer mortality in the US male general population between 1999 and 2019 . The proportion of each cause of death in the overall cohort and subgroups (categorized by age at diagnosis, marital status, race, year of diagnosis, grade, laterality, stage, surgery, radiation, and chemotherapy) was calculated. Cumulative mortality rates by follow-up time were calculated and cumulative mortality curves were generated with the competing risk method. Additionally, we calculated SMRs for CVD in different age groups. SMR in this study represented the CVD risk of MBC patients compared to the US general population. The primary endpoint in this study was death from any cause including cardiovascular diseases. Causes of death were classified according to the SEER Cause of Death Recode - which is based on the World Health Organization International Statistical Classification of Diseases and Related Health Problems (8th, 9th, and 10th Revisions) ${ }^{22}$-into 10 categories as previously described $^{23}$ (Supplemental Table 1). Patients who were still alive at the last follow-up were considered as censored observations. The follow-up period was the time from the date of first diagnosis with $\mathrm{MBC}$ to the date of death or last follow-up. The final follow-up date was December 31, 2016. 


\section{Statistical Analysis}

Time trends of MBC mortality were analyzed using Joinpoint v4.8.0.1 software (Statistical Research and Applications Branch, National Cancer Institute, USA) (https://surveil lance.cancer.gov/joinpoint/). The proportion of each cause of death was calculated using Excel software (Microsoft, Redmond, WA, USA). Cumulative mortality rates were calculated with the competing risk model using $\mathrm{R}$ v4.0.3 software (https://www.r-project.org). SMR was calculated as the ratio of observed to expected deaths; the latter was calculated as person-years multiplied by the rate of CVD in the general population obtained from CDC WONDER, and person-years was the sum of MBC patients' survival time- ie, the interval from $\mathrm{MBC}$ diagnosis to CVD or the last follow-up of the study. The $95 \%$ confidence interval $(95 \% \mathrm{CI})$ and $P$ value of SMRs were calculated as previously described. ${ }^{24,25} P<0.05$ was considered statistically significant.

\section{Results}

\section{Baseline Characteristics of the Study Population}

There were 6426 eligible patients diagnosed with MBC between 1975 and 2016 in the SEER database; 3068 (47.7\%) died during the follow-up period. Patients' baseline characteristics are shown in Table 1 . The median age at diagnosis was 65 years. Most patients $(87.0 \%)$ were diagnosed between the age of 45 and 84 years. A higher proportion of young patients survived while a higher proportion of elderly patients died. Most patients $(82.7 \%)$ were diagnosed between 1995 and 2016. Of the patients who died, 67.4\% were diagnosed between 1995 and 2016; on the other hand, $96.7 \%$ of survivors were diagnosed between 1995 and 2016 . White patients made up the majority (80.4\%) of the cohort. Most patients had localized (40.2\%) or regional (40.8\%) disease; about half $(50.4 \%)$ had low-grade tumors; and most $(89.8 \%)$ received surgery, whereas radiotherapy $(26.0 \%)$ and chemotherapy $(35.0 \%)$ were less frequently used.

\section{Time Trends of MBC Mortality}

The final selected model showed one joinpoint, indicating that MBC mortality rate did not change significantly between 1999 and 2004 (annual percentage change $[\mathrm{APC}]=-2.92$, $95 \%$ CI: $-6.20,0.50)$. However, on average, the crude rate of MBC mortality increased by $1.16 \%$ each year between 2004 and 2019 (APC=1.16, 95\% CI: 0.50, 1.80) (Figure 1).
Table I Characteristics of Male Breast Cancer Patients

\begin{tabular}{|c|c|c|c|}
\hline Characteristics & $\begin{array}{l}\text { No. of Cancer } \\
\text { Patients (\% in the } \\
\text { Overall Cohort) }\end{array}$ & $\begin{array}{l}\text { No. of } \\
\text { Death (\%) }\end{array}$ & $\begin{array}{l}\text { No. of } \\
\text { Alive (\%) }\end{array}$ \\
\hline All patients & 6426 & 3068 & 3358 \\
\hline $\begin{array}{l}\text { Age at diagnosis } \\
\text { Median age } \\
0-34 \\
35-44 \\
45-54 \\
55-64 \\
65-74 \\
75-84 \\
85+\end{array}$ & $\begin{array}{l}65 \\
70(1.1) \\
324(5.0) \\
967(15.0) \\
1683(26.2) \\
1746(27.2) \\
1193(18.6) \\
443(6.9)\end{array}$ & $\begin{array}{l}18(0.6) \\
105(3.4) \\
335(10.9) \\
651(21.2) \\
828(27.0) \\
784(25.6) \\
347(11.3)\end{array}$ & $\begin{array}{l}52(1.6) \\
219(6.5) \\
632(18.8) \\
1032(30.7) \\
918(27.3) \\
409(12.2) \\
96(2.9)\end{array}$ \\
\hline $\begin{array}{l}\text { Year of } \\
\text { diagnosis } \\
1975-1984 \\
1985-1994 \\
1995-2004 \\
2005-2016\end{array}$ & $\begin{array}{l}450(7.0) \\
661(10.3) \\
1545(24.0) \\
3770(58.7)\end{array}$ & $\begin{array}{l}429(14.0) \\
570(18.6) \\
1017(33.1) \\
1052(34.3)\end{array}$ & $\begin{array}{l}21(0.6) \\
91(2.7) \\
528(15.7) \\
2718(81.0)\end{array}$ \\
\hline $\begin{array}{l}\text { Race } \\
\text { White } \\
\text { Black } \\
\text { Others }{ }^{\mathrm{a}} \\
\text { Unknown }\end{array}$ & $\begin{array}{l}5167(80.4) \\
873(13.6) \\
332(5.2) \\
54(0.8)\end{array}$ & $\begin{array}{l}2504(81.6) \\
449(14.7) \\
111(3.6) \\
4(0.1)\end{array}$ & $\begin{array}{l}2663(79.3) \\
424(12.6) \\
221(6.6) \\
50(1.5)\end{array}$ \\
\hline $\begin{array}{l}\text { Marital status } \\
\text { Married } \\
\text { Unmarried } \\
\text { Unknown }\end{array}$ & $\begin{array}{l}4160(64.7) \\
1903(29.6) \\
363(5.7)\end{array}$ & $\begin{array}{l}1872(61.0) \\
1050(34.2) \\
146(4.8)\end{array}$ & $\begin{array}{l}2288(68.1) \\
853(25.4) \\
217(6.5)\end{array}$ \\
\hline $\begin{array}{l}\text { Stage } \\
\text { Localized } \\
\text { Regional } \\
\text { Distant } \\
\text { Unknown }\end{array}$ & $\begin{array}{l}2583(40.2) \\
2623(40.8) \\
601(9.4) \\
619(9.6)\end{array}$ & $\begin{array}{l}1038(33.8) \\
1394(45.4) \\
496(16.2) \\
140(4.6)\end{array}$ & $\begin{array}{l}1545(46.0) \\
1229(36.6) \\
105(3.1) \\
479(14.3)\end{array}$ \\
\hline $\begin{array}{l}\text { Grade }^{\mathbf{b}} \\
\text { Low } \\
\text { High } \\
\text { Others }^{c} \\
\text { Unknown }\end{array}$ & $\begin{array}{l}3239(50.4) \\
2005(31.2) \\
62(1.0) \\
1120(17.4)\end{array}$ & $\begin{array}{l}1200(39.1) \\
1018(33.2) \\
30(1.0) \\
820(26.7)\end{array}$ & $\begin{array}{l}2039(60.7) \\
987(29.4) \\
32(1.0) \\
300(8.9)\end{array}$ \\
\hline $\begin{array}{l}\text { Laterality } \\
\text { Left } \\
\text { Right } \\
\text { One side but } \\
\text { unspecified } \\
\text { Paired side }\end{array}$ & $\begin{array}{l}3322(51.7) \\
3045(47.4) \\
10(0.1) \\
49(0.8)\end{array}$ & $\begin{array}{l}1566(51.1) \\
146 \mid(47.6) \\
7(0.2) \\
34(1.1)\end{array}$ & $\begin{array}{l}1756(52.3) \\
1584(47.2) \\
3(0.1) \\
15(0.4)\end{array}$ \\
\hline $\begin{array}{l}\text { Surgery } \\
\text { Yes } \\
\text { No } \\
\text { Unknown }\end{array}$ & $\begin{array}{l}5767(89.8) \\
605(9.4) \\
54(0.8)\end{array}$ & $\begin{array}{l}2637(86.0) \\
405(13.2) \\
26(0.8)\end{array}$ & $\begin{array}{l}3130(93.2) \\
200(6.0) \\
28(0.8)\end{array}$ \\
\hline
\end{tabular}

(Continued) 
Table I (Continued).

\begin{tabular}{|c|l|l|l|}
\hline Characteristics & $\begin{array}{l}\text { No. of Cancer } \\
\text { Patients (\% in the } \\
\text { Overall Cohort) }\end{array}$ & $\begin{array}{l}\text { No. of } \\
\text { Death (\%) }\end{array}$ & $\begin{array}{l}\text { No. of } \\
\text { Alive (\%) }\end{array}$ \\
\hline $\begin{array}{c}\text { Radiation } \\
\text { Yes } \\
\text { None/Unknown }\end{array}$ & $\begin{array}{l}1669(26.0) \\
\begin{array}{c}\text { Chemotherapy } \\
\text { Yes }\end{array}\end{array}$ & $\begin{array}{l}779(25.4) \\
2289(74.6)\end{array}$ & $\begin{array}{l}890(26.5) \\
2468(73.5)\end{array}$ \\
\hline None/Unknown & $4179(65.0)$ & $896(29.2)$ & $1351(40.2)$ \\
\hline
\end{tabular}

Notes: ${ }^{a}$ Others include American Indian/Alaska Native and Asian/Pacific Islander. bLow (Grade I, well-differentiated and Grade II, moderately differentiated) and high (Grade III, poorly differentiated and Grade IV, undifferentiated). 'Others include $B$ cell, pre-B cell, B precursor cell, and T cell neoplasms.

The crude rate of MBC mortality increased significantly from 0.26 per 100,000 in 2004 to 0.31 per 100,000 in 2019.

\section{Causes of Death in MBC Patients}

Among patients who died in the overall cohort, 1311 (42.7\%) died of breast cancer and 1757 (57.3\%) died of non-breast cancer causes including CVD (26.9\%), other cancers $(6.7 \%)$, respiratory disease $(6.1 \%)$, and nervous system disease (1.8\%) (Supplemental Table 2). The proportion of breast cancer deaths decreased whereas that of CVDs increased with age (Figure 2). The proportion of CVDs was much higher than breast cancer deaths $(38.5 \%$ vs $21.4 \%$ ) among patients with localized disease (Figure 2A). For patients $\geq 75$ years old, CVD was more common than breast cancer death and was the leading cause of death (Figure 2B). In the subgroup analyses, the proportion of CVDs increased with age in both localized and regional disease stage subgroups (Figure $2 \mathrm{C}$ and $\mathrm{D}$ ), with CVD more frequently observed in patients with localized cancer than in age-matched patients with regional cancer. Similarly, the proportion of CVDs increased with age in both low- and high-grade subgroups, with a higher percentage of CVDs in low-grade cancer patients as compared to age-matched high-grade cancer patients (Figure 2E and F). Furthermore, in the localized or lowgrade cancer subgroups, CVD was the leading cause of death in patients aged $\geq 65$ years. Causes of death in other subgroups are shown in Supplemental Figure 1.

\section{Cumulative Mortality Rates by Cause of Death}

The competing risk model confirmed the risk of all competing events and showed cumulative mortality with follow-up time (Figure 3). We found that risk of death from breast cancer was much higher than from other competing causes in patients aged 35-64 years (Figure 3A); CVD risk increased and was the second most common cause of death in patients aged 65-79 years (Figure 3B), followed by other non-cancer causes of death; meanwhile, CVD was the leading cause of death in patients aged $80+$ years (Figure 3C). The same trend was observed in patients with different stages of cancer: CVD was the leading cause of death in patients with localized disease although other noncancer deaths were also important (Figure 3D). Patients with regional or distant cancer had a higher risk of breast cancer death (Figure 3E and F). Regarding racial differences in mortality rates, the competing risk model indicated that Black patients had a higher risk of breast cancer death than those who were White or of other races (Figure 3G-I). Patients with low-grade cancer had a higher risk of CVD compared to those with high-grade cancer (Figure $3 \mathrm{~J}$ and $\mathrm{K}$ ). Cumulative mortality rates in the overall cohort for different follow-up times are shown in Supplemental Table 3, and the rates in patients aged $80+$ years or with localized cancer are shown in Supplemental Tables 4 and 5, respectively.

\section{MBC Patients' CVD Risk Compared to the General Population}

SMRs of CVD are listed in Table 2. In the overall cohort, MBC patients' CVD risk was 6.58-fold higher than that of the general population (SMR $=6.58,95 \% \mathrm{CI}: 6.14,7.05)$. Young patients (35-44 years old) had the highest CVD risk compared to the age-matched general population (SMR $=14.45,95 \%$ CI: 5.79, 29.78). SMRs decreased with age: in MBC patients aged $85+$ years, CVD risk was 1.71-fold higher than that of the general population (SMR $=1.71,95 \%$ CI: $1.45,2.01)$.

\section{Discussion}

In this population-based study, we found that MBC mortality in the US population has been increasing since 2004. Non-breast cancer death, especially CVD, accounted for a high proportion of deaths in MBC patients; for elderly patients or those with localized disease, CVD was the leading cause of death. Compared to the age-matched general population, MBC patients - especially those of a young age - had elevated CVD risk. This is the first 


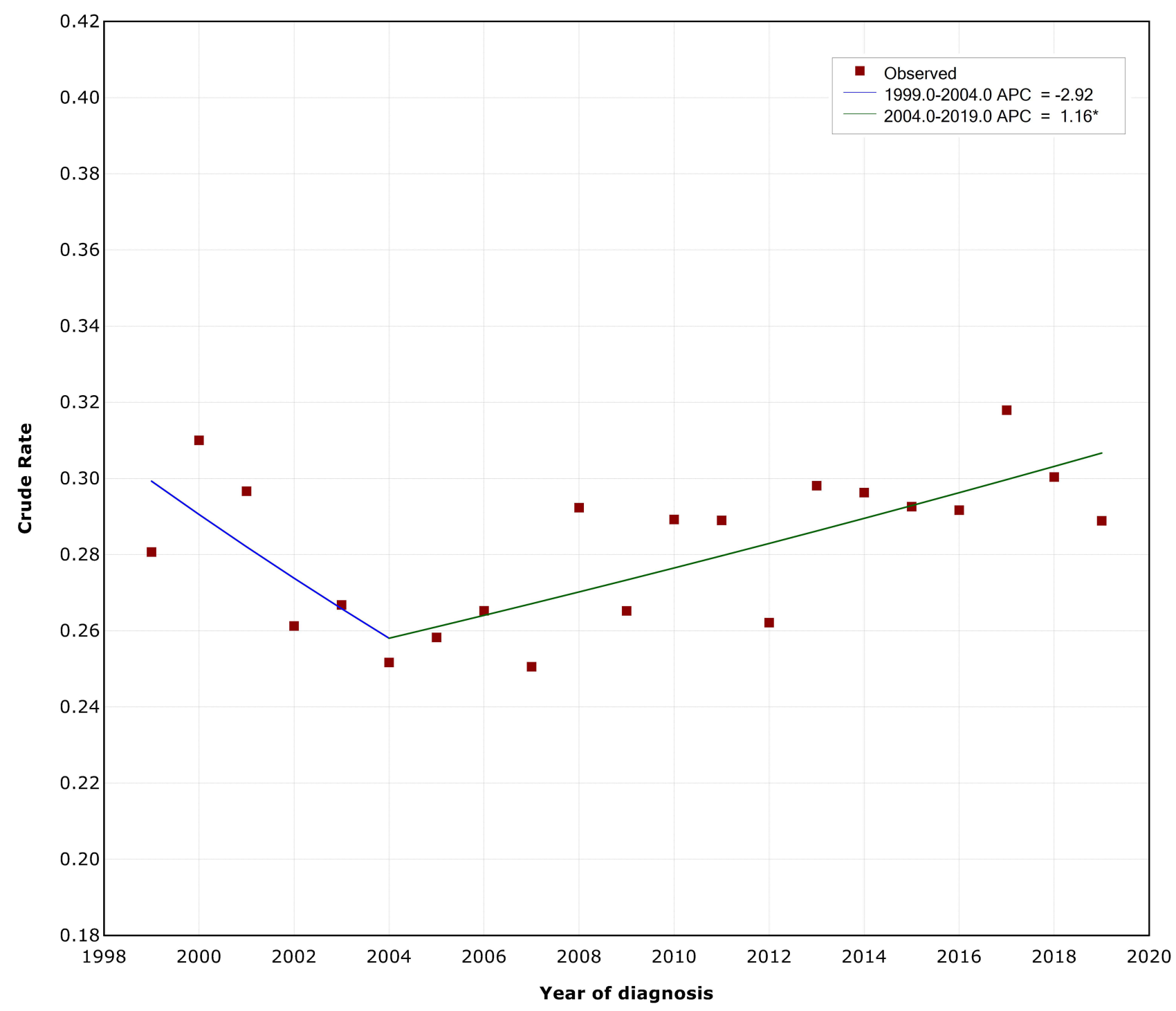

Figure I Trends in MBC mortality in the US population.

Notes: *APC differs significantly from zero at the alpha $=0.05$ level. Final selected model: $I$ joinpoint.

study to analyze the causes of death and CVD risk in MBC at the population level.

Non-breast cancer death accounted for a high proportion of deaths in $\mathrm{MBC}$ patients, exceeding breast cancer deaths. In the overall cohort of MBC patients, the top 3 causes of death were breast cancer, CVD, and other cancers. As one cause of death precludes others, they were considered as competing events. We used a competing risk model to evaluate the risks of different causes of death and calculated cumulative mortality rates, which ensured the accuracy of our results. ${ }^{26}$ Our findings are supported in part by the study of Donegan et al, which showed that heart diseases and other cancers were the most common non cancer causes of death ${ }^{17}$ and by the study of Gnerlich et al, in which the proportion of non-breast cancer deaths exceeded that of breast cancer deaths. ${ }^{27}$ However, the former study had a small sample size and only analyzed the proportion of death, whereas the latter did not provide detailed causes of death. In the present investigation, we analyzed population-based epidemiologic data that included detailed causes of death, for which we calculated competing risks and cumulative mortality rates.

CVD was the leading cause of death in elderly patients or patients with localized disease. This is in line with earlier studies on FBC. An investigation based on the SEER-Medicare database found that CVD was the leading cause of death among elderly or early-stage FBC patients, ${ }^{13}$ while another reported that cardiovascular 
A

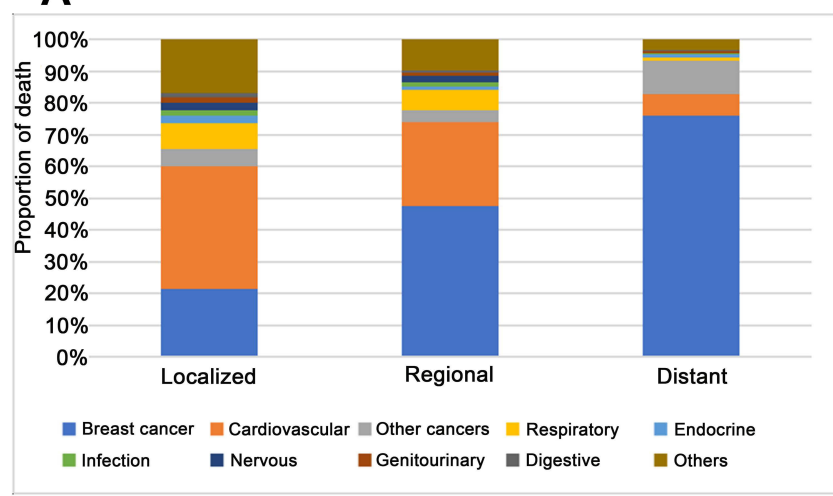

\section{C}

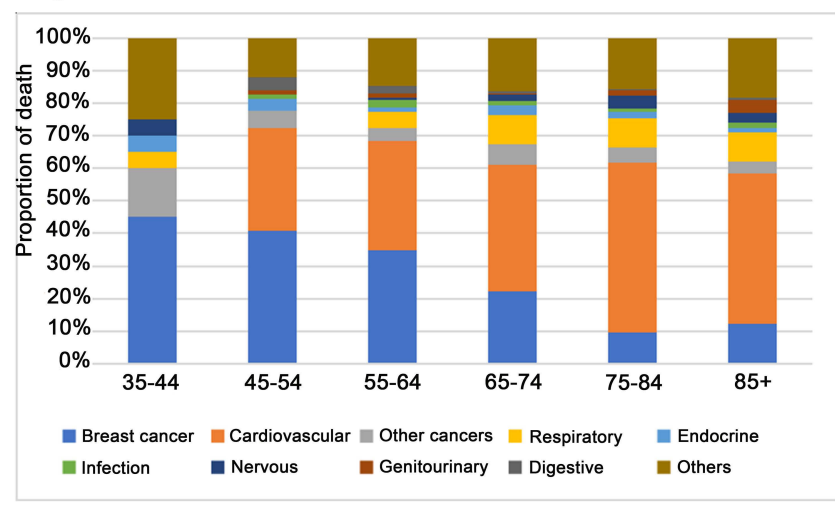

$E$

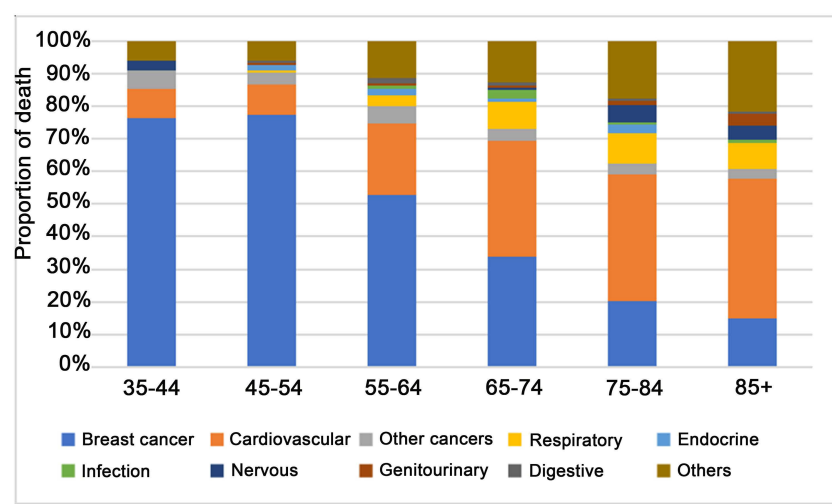

B

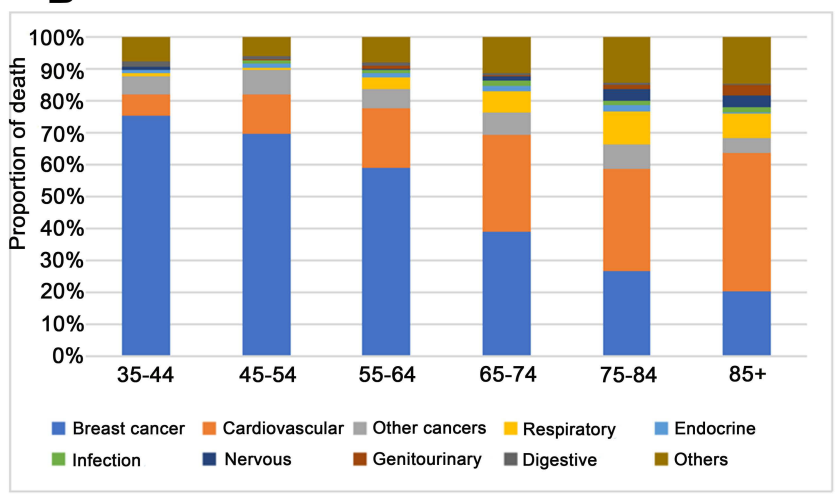

D

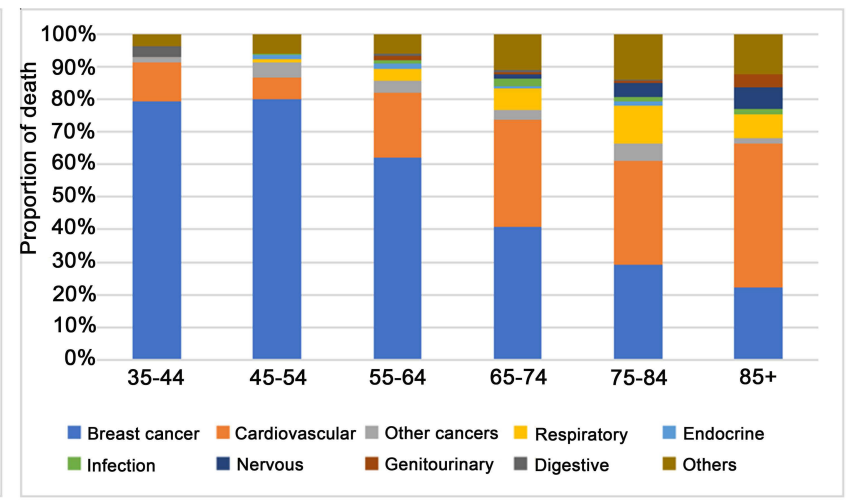

\section{$\mathbf{F}$}

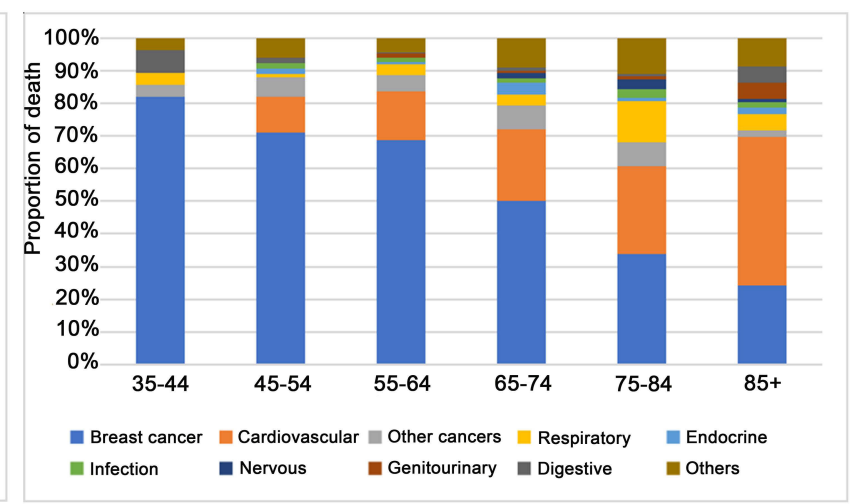

Figure 2 Proportion of each cause of death in different MBC patient subgroups. (A) Patients at different disease stages. (B) Patients by age group. (C and D) Localized (C) and regional (D) stage patients by age group. (E and $\mathbf{F})$ Low-grade $(\mathbf{E})$ and high-grade $(\mathbf{F})$ patients by age group.

disease risk was equal to or higher than breast cancer recurrence risk in $80 \%$ of postmenopausal patients with hormone receptor-positive FBC 10 years after diagnosis. ${ }^{14}$ We found that MBC patients had a higher CVD risk than the general population based on calculated SMRs. Similarly, a large-scale SEER-based study showed that CVD risk was 1.62- to 90.07-fold higher in FBC patients than in the general population. ${ }^{12}$ It is worth noting that SMR decreased with age in our study - that is, compared to the age-matched general population, young $\mathrm{MBC}$ patients had a much higher CVD risk whereas the disparity was less obvious in the elderly population. Similar trends have been reported in $\mathrm{FBC}^{12}$ and other cancers, ${ }^{28}$ possibly because CVD risk is high among the elderly in the general population. Our results suggest that CVD risk should also be monitored and managed in younger patients.

The high CVD rate in MBC patients may be explained by cardiotoxic anticancer treatments and high prevalence of 
A

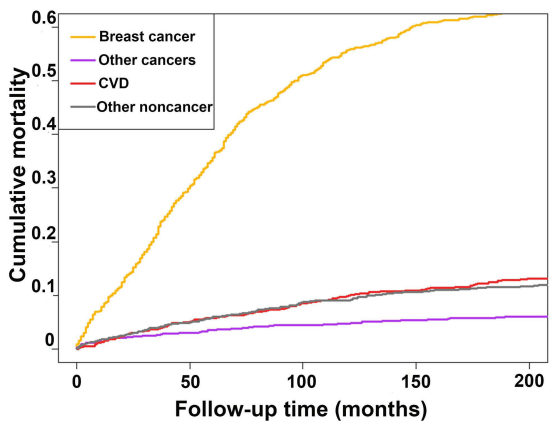

D

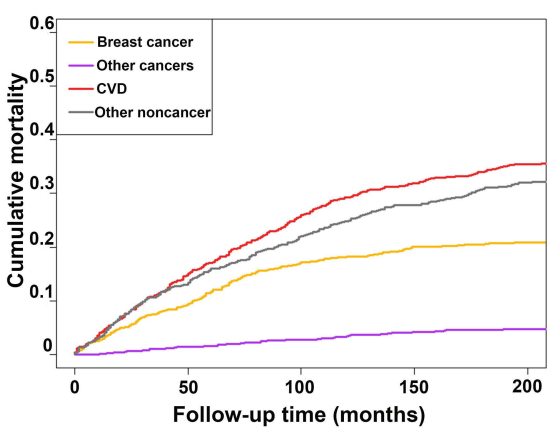

G

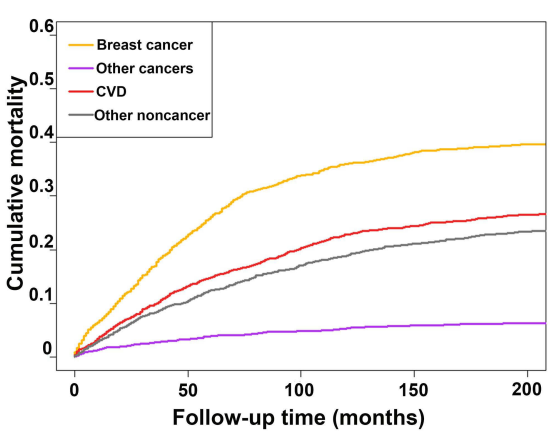

J

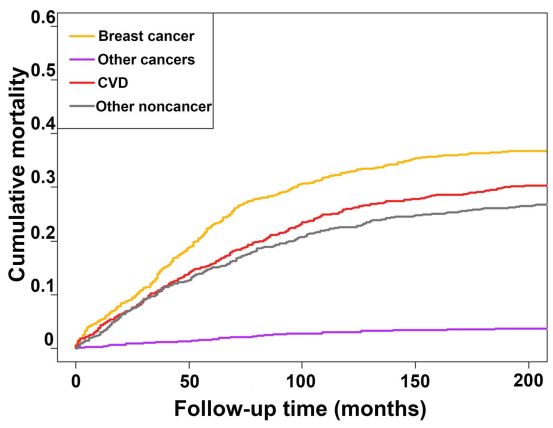

B

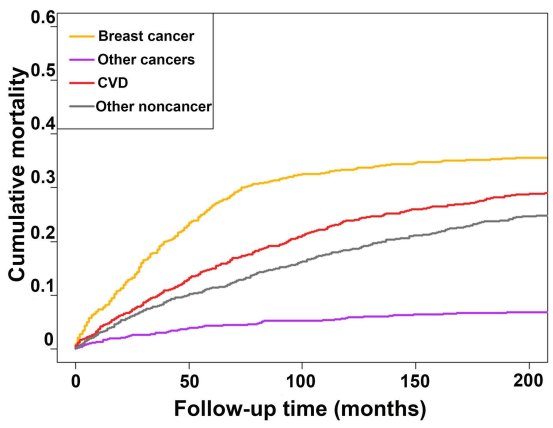

E

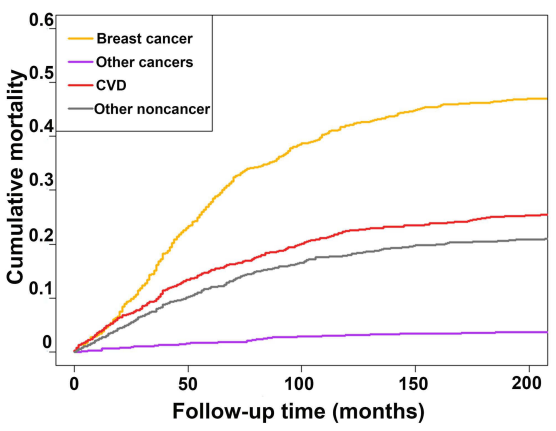

H

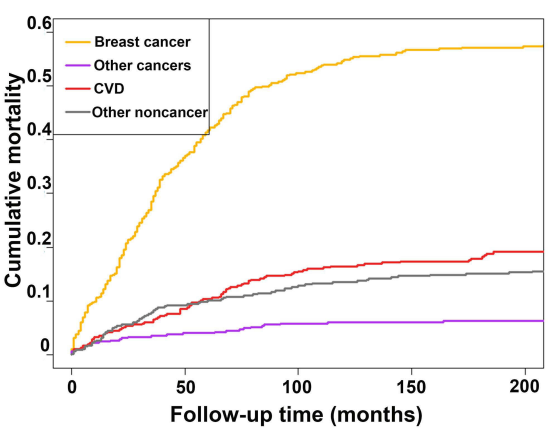

K

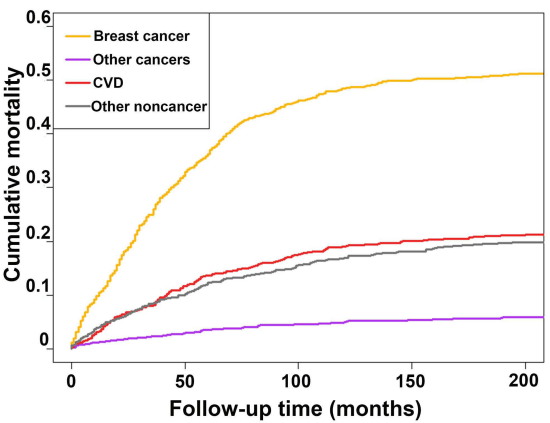

C

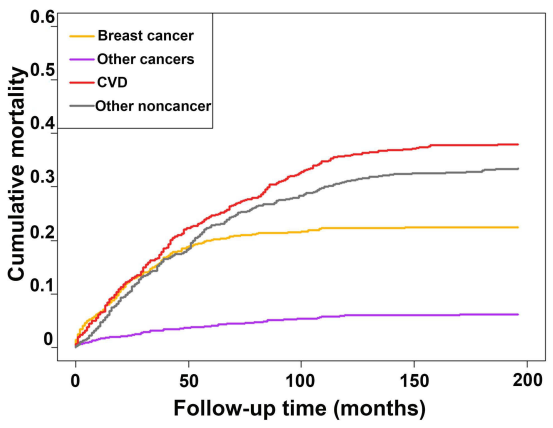

$\mathbf{F}$

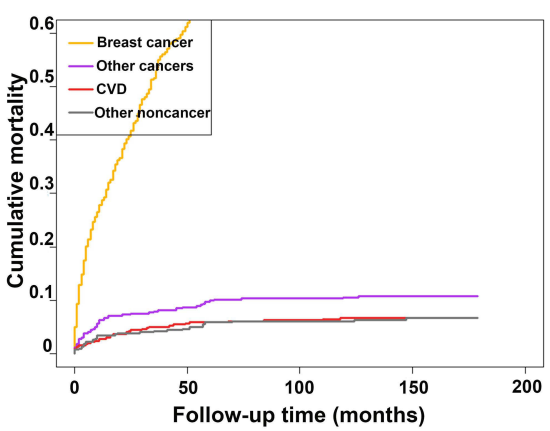

I

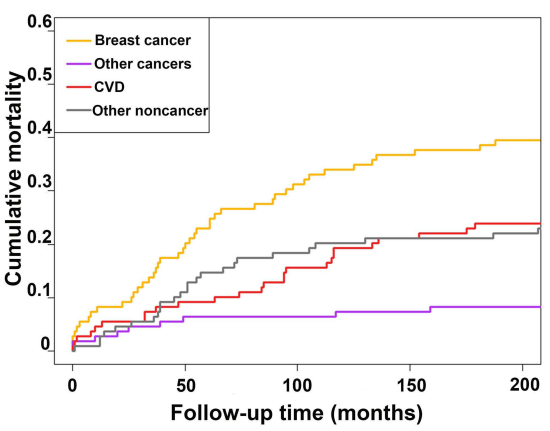

Figure 3 Cumulative mortality curves by follow-up time in different MBC patient subgroups. (A-C) Patients aged 35-64 years (A), 65-79 years (B), and 80+ years (C). (DF) Patients with localized (D), regional $(\mathbf{E})$, and distant $(\mathbf{F})$ cancer. $(\mathbf{G}-\mathbf{I})$ White $(\mathbf{G})$, black $(\mathbf{H})$, and other ethnic group $(\mathbf{I})$ patients. $(\mathbf{J}$ and $\mathbf{K})$ Patients with low-grade $(\mathbf{J})$ and high-grade (K) cancer.

cardiovascular comorbidities. In one study, $97.4 \%$ of MBC patients were estrogen receptor-positive and most received tamoxifen therapy. ${ }^{29}$ Side effects of tamoxifen include thromboembolism and cardiovascular problems; ${ }^{29,30}$ moreover, elderly MBC patients have an increased risk of arterial thromboembolism. ${ }^{31}$ Chemotherapy is a risk factor for CVD, 
Table 2 Age-Specific Cardiovascular Death-Related Standardized Mortality Ratios in Male Breast Cancer Patients

\begin{tabular}{|l|c|c|c|c|}
\hline Age Group & O & E & SMR $(95 \%$ CI) & $P$ value \\
\hline $35-44$ & 7 & 0.48 & $14.45(5.79-29.78)$ & $<0.00 \mathrm{I}$ \\
$45-54$ & $4 I$ & 5.52 & $7.43(5.33-10.08)$ & $<0.00 \mathrm{I}$ \\
$55-64$ & 123 & 21.77 & $5.65(4.70-6.74)$ & $<0.00 \mathrm{I}$ \\
$65-74$ & $25 \mathrm{I}$ & 50.32 & $4.99(4.39-5.64)$ & $<0.00 \mathrm{I}$ \\
$75-84$ & 252 & 95.05 & $2.65(2.33-3.00)$ & $<0.00 \mathrm{I}$ \\
$85+$ & 150 & 87.69 & $1.7 \mathrm{I}(1.45-2.01)$ & $<0.00 \mathrm{I}$ \\
Overall & 824 & 125.16 & $6.58(6.14-7.05)$ & $<0.00 \mathrm{I}$ \\
\hline
\end{tabular}

Abbreviations: $\mathrm{Cl}$, confidence interval; $\mathrm{E}$, expected number of deaths; $\mathrm{O}$, observed number of deaths; SMR, standardized mortality ratio.

as it was shown to be cardiotoxic and increase the risk of cardiac dysfunction in FBC patients. ${ }^{16}$ Compared to female lymphoma patients, male patients who received chemotherapy had an elevated risk of cardiac events. ${ }^{32}$ Radiotherapy causes inflammation, endothelial damage, and atherosclerosis, which increase the risk of cardiovascular events. ${ }^{16}$ Because of their older age, MBC patients may be more likely to have cardiovascular comorbidities than FBC patients. ${ }^{33}$

We examined causes of death in different subgroups of MBC patients. Our results were in line with those of a previous study demonstrating that Black men had a higher breast cancer mortality rate, which may be attributable to lower income and a lack of health insurance. ${ }^{34}$ Patients with low-grade tumors had a higher CVD rate, possibly because they live longer and have more time to experience cardiovascular events. Our results indicate that more attention should be paid to the prevention of breast cancer death in Black men and of CVD in MBC patients who are elderly, have localized or low-grade cancer.

This study had some limitations. Firstly, treatment and nursing practices have changed over the last 4 decades, which could affect the causes of death in MBC patients; however, this could not be verified as detailed treatment and nursing information was not available in the SEER database. Nonetheless, we did analyze causes of death in different years of diagnosis. Secondly, the SEER database does not provide comorbidity information for patients, which precluded an analysis of the effect of comorbidities on different causes of death. On the other hand, the main purpose of the present epidemiologic study was to analyze the major causes of death in $\mathrm{MBC}$ patients and not to identify prognostic factors.

\section{Conclusion}

The results of this study demonstrate that more $\mathrm{MBC}$ patients die from causes other than breast cancer than from the disease itself, and that CVD is the leading cause of death in patients who are old or have localized disease. Our findings highlight the importance of monitoring not only breast cancer but also other risk factors for death-especially cardiovascular comorbidities - in these patients.

\section{Abbreviations}

APC, annual percentage change; ASCO, American Society of Clinical Oncology; CDC, Centers for Disease Control and Prevention; CI, confidence interval; CVD, cardiovascular death; FBC, female breast cancer; MBC, male breast cancer; SEER, Surveillance, Epidemiology, and End Results; SMR, standardized mortality ratio; WONDER, Wide-ranging Online Data for Epidemiologic Research.

\section{Data Sharing Statement}

The datasets analyzed in the current study are publicly available from the SEER database (http://seer.cancer.gov).

\section{Statement of Ethics}

Ethics approval was not required because the analyzed data are publicly available.

\section{Acknowledgments}

We thank all the staffs from the SEER and CDC WONDER for providing the research data.

\section{Funding}

This study was funded by the National College Students' Innovation Entrepreneurship Training Plan Program of China (grant no. 202010570007); Special Funds for the Cultivation of Guangdong College Students' Scientific and Technological Innovation. (“Climbing Program” Special Funds; grant no. pdjh2020a0478); and Guangzhou Medical University College Students Science Technology Innovation Project (grant nos. 2019C002, 2019A021, and 2020A026).

\section{Disclosure}

The authors have no conflicts of interest to declare.

\section{References}

1. Giordano SH, Longo DL. Breast cancer in men. $N$ Engl $J$ Med. 2018;378(24):2311-2320. doi:10.1056/NEJMra1707939

2. Abdelwahab Yousef AJ. Male breast cancer: epidemiology and risk factors. Semin Oncol. 2017;44(4):267-272. doi:10.1053/j.seminoncol. 2017.11.002

3. Siegel RL, Miller KD, Fuchs HE, Jemal A. Cancer statistics, 2021. $C A$ Cancer J Clin. 2021;71(1):7-33. doi:10.3322/caac.21654 
4. Konduri S, Singh M, Bobustuc G, Rovin R, Kassam A. Epidemiology of male breast cancer. Breast. 2020;54:8-14. doi:10.1016/j.breast.2020.08.010

5. Speirs V, Shaaban AM. The rising incidence of male breast cancer. Breast Cancer Res Treat. 2009;115(2):429-430. doi:10.1007/s10549008-0053-y

6. Reddington R, Galer M, Hagedorn A, et al. Incidence of male breast cancer in Scotland over a twenty-five-year period (1992-2017). Eur J Surg Oncol. 2020;46(8):1546-1550. doi:10.1016/j.ejso.2020.01.009

7. Hassett MJ, Somerfield MR, Baker ER, et al. Management of male breast cancer: ASCO guideline. J Clin Oncol. 2020;38:1849-1863.

8. Piscuoglio S, Ng CK, Murray MP, et al. The genomic landscape of male breast cancers. Clin Cancer Res. 2016;22(16):4045-4056. doi:10.1158/1078-0432.CCR-15-2840

9. Masci G, Caruso M, Caruso F, et al. Clinicopathological and immunohistochemical characteristics in male breast cancer: a retrospective case series. Oncologist. 2015;20(6):586-592. doi:10.1634/theoncologist.2014-0243

10. Gucalp A, Traina TA, Eisner JR, et al. Male breast cancer: a disease distinct from female breast cancer. Breast Cancer Res Treat. 2019;173(1):37-48. doi:10.1007/s10549-018-4921-9

11. Fentiman IS. Male breast cancer is not congruent with the female disease. Crit Rev Oncol Hematol. 2016;101:119-124. doi:10.1016/j. critrevonc.2016.02.017

12. Zaorsky NG, Churilla TM, Egleston BL, et al. Causes of death among cancer patients. Ann Oncol. 2017;28(2):400-407. doi:10.1093/annonc/mdw604

13. Patnaik JL, Byers T, DiGuiseppi C, Dabelea D, Denberg TD. Cardiovascular disease competes with breast cancer as the leading cause of death for older females diagnosed with breast cancer: a Retrospective Cohort Study. Breast Cancer Res. 2011;13(3):R64. doi:10.1186/bcr2901

14. Bardia A, Arieas ET, Zhang Z, et al. Comparison of breast cancer recurrence risk and cardiovascular disease incidence risk among postmenopausal women with breast cancer. Breast Cancer Res Treat. 2012;131(3):907-914. doi:10.1007/s10549-011-1843-1

15. Runowicz CD, Leach CR, Henry NL, et al. American cancer society/ American society of clinical oncology breast cancer survivorship care guideline. $J$ Clin Oncol. 2016;34(6):611-635. doi:10.1200/ JCO.2015.64.3809

16. Mehta LS, Watson KE, Barac A, et al. Cardiovascular disease and breast cancer: where these entities intersect: a scientific statement from the American heart association. Circulation. 2018;137(8):e30e66. doi:10.1161/CIR.0000000000000556

17. Donegan WL, Redlich PN, Lang PJ, Gall MT. Carcinoma of the breast in males: a multiinstitutional survey. Cancer. 1998;83 (3):498-509. doi:10.1002/(SICI)1097-0142(19980801)83:3<498:: AID-CNCR19>3.0.CO;2-R

18. Kwong A, Chau WW, Mang OW, et al. Male breast cancer: a population-based comparison with female breast cancer in Hong Kong, Southern China: 1997-2006. Ann Surg Oncol. 2014;21 (4):1246-1253. doi:10.1245/s10434-013-3377-8

19. Anderson WF, Jatoi I, Tse J, Rosenberg PS. Male breast cancer: a population-based comparison with female breast cancer. J Clin Oncol. 2010;28(2):232-239. doi:10.1200/JCO.2009.23.8162
20. National Cancer Institute Surveillance, Epidemiology, and End Results Program. SEER data \& software. Available from: https:// seer.cancer.gov/data-software/. Accessed February 19, 2021.

21. Centers for Disease Control and Prevention. About multiple cause of death, 1999-2019. Available from: https://wonder.cdc.gov/mcdicd10.html. Accessed February 19, 2021.

22. National Cancer Institute Surveillance, Epidemiology, and End Results Program. SEER cause of death recode 1969+ (03/01/2018) SEER data reporting tools. Available from: https://seer.cancer.gov/ codrecode/1969_d03012018/index.html. Accessed February 19, 2021.

23. Ye Y, Otahal P, Marwick TH, Wills KE, Neil AL, Venn AJ. Cardiovascular and other competing causes of death among patients with cancer from 2006 to 2015: an Australian Population-Based Study. Cancer. 2019;125(3):442-452. doi:10.1002/cncr.31806

24. Altman DG, Bland JM. How to obtain the $P$ value from a confidence interval. BMJ. 2011;343(aug08 1):d2304. doi:10.1136/bmj.d2304

25. Breslow NE, Day NE. Statistical methods in cancer research. Volume II - the design and analysis of cohort studies. IARC Sci Publ. 1987;82:1-406.

26. Lau B, Cole SR, Gange SJ. Competing risk regression models for epidemiologic data. Am J Epidemiol. 2009;170(2):244-256. doi:10.1093/aje/kwp107

27. Gnerlich JL, Deshpande AD, Jeffe DB, Seelam S, Kimbuende E, Margenthaler JA. Poorer survival outcomes for male breast cancer compared with female breast cancer may be attributable to in-stage migration. Ann Surg Oncol. 2011;18:1837-1844.

28. Sturgeon KM, Deng L, Bluethmann SM, et al. A population-based study of cardiovascular disease mortality risk in US cancer patients. Eur Heart J. 2019;40(48):3889-3897. doi:10.1093/eurheartj/ehz766

29. Eggemann H, Brucker C, Schrauder M, et al. Survival benefit of tamoxifen in male breast cancer: prospective cohort analysis. $\mathrm{Br}$ $J$ Cancer. 2020;123(1):33-37. doi:10.1038/s41416-020-0857-z

30. Eggemann H, Bernreiter AL, Reinisch M, et al. Tamoxifen treatment for male breast cancer and risk of thromboembolism: prospective cohort analysis. Br J Cancer. 2019;120(3):301-305. doi:10.1038/ s41416-018-0369-2

31. Reiner AS, Navi BB, DeAngelis LM, Panageas KS. Increased risk of arterial thromboembolism in older men with breast cancer. Breast Cancer Res Treat. 2017;166(3):903-910. doi:10.1007/s10549-0174433-z

32. Myrehaug S, Pintilie M, Yun L, et al. A population-based study of cardiac morbidity among Hodgkin lymphoma patients with preexisting heart disease. Blood. 2010;116(13):2237-2240. doi:10.1182/ blood-2010-01-263764

33. Fentiman IS, Fourquet A, Hortobagyi GN. Male breast cancer. Lancet. 2006;367(9510):595-604. doi:10.1016/S0140-6736(06) 68226-3

34. Crew KD, Neugut AI, Wang X, et al. Racial disparities in treatment and survival of male breast cancer. J Clin Oncol. 2007;25 (9):1089-1098. doi:10.1200/JCO.2006.09.1710
Clinical Interventions in Aging

\section{Publish your work in this journal}

Clinical Interventions in Aging is an international, peer-reviewed journal focusing on evidence-based reports on the value or lack thereof of treatments intended to prevent or delay the onset of maladaptive correlates of aging in human beings. This journal is indexed on PubMed Central, MedLine, CAS, Scopus and the Elsevier
Bibliographic databases. The manuscript management system is completely online and includes a very quick and fair peer-review system, which is all easy to use. Visit http://www.dovepress.com/ testimonials.php to read real quotes from published authors. 